\title{
Perceptions of trained laypersons in end-of-life or advance care planning conversations: a qualitative meta-synthesis
}

Elizabeth Somes ${ }^{1 \dagger}$, Joanna Dukes ${ }^{2 \dagger}$, Adreanne Brungardt ${ }^{4}$, Sarah Jordan ${ }^{4}$, Kristen DeSanto ${ }^{5}$, Christine D. Jones $^{6}$, Urvi Jhaveri Sanghvi ${ }^{7}$, Khadijah Breathett ${ }^{8}$, Jacqueline Jones ${ }^{7}$ and Hillary D. Lum ${ }^{3,4^{*}}$

\begin{abstract}
Background: Laypersons including volunteers, community health navigators, or peer educators provide important support to individuals with serious illnesses in community or healthcare settings. The experiences of laypersons in communication with seriously ill peers is unknown.

Methods: We performed an ENTREQ-guided qualitative meta-synthesis. We conducted a systematic search of MEDLINE, PsycINFO, CINAHL, Cochrane Library, and AMED to include qualitative studies with data regarding communication and laypersons in advance care planning, palliative care, or end-of-life settings. Study quality was appraised using a standardized tool. The analysis identified key domains and associated themes relating specifically to laypersons' perspectives on communication.

Results: Of 877 articles, nine studies provided layperson quotations related to layperson-to-peer communication associated with advance care planning $(n=4)$ or end-of-life conversations $(n=5)$. The studies were conducted in United Kingdom $(n=4)$ or United States settings $(n=5)$. The synthesis of layperson perspectives yielded five main domains: 1) layperson-to-peer communication, focusing on the experience of talking with peers, 2) layperson-topeer interpersonal interactions, focusing on the entire interaction between the layperson and peers, excluding communication-related issues, 3) personal impact on the layperson, 4) layperson contributions, and 5) layperson training. Laypersons described using specific communication skills including the ability to build rapport, discuss sensitive issues, listen and allow silence, and respond to emotions.
\end{abstract}

Conclusions: Published studies described experiences of trained laypersons in conversations with peers related to advance care planning or end-of-life situations. Based on these layperson perspectives related to communication, programs should next evaluate the potential impact of laypersons in meaningful conversations.

Keywords: Volunteers, Communication, Hospice care, Palliative care, Terminal care, Lay health navigators, Advance care planning, Peer educators

\footnotetext{
* Correspondence: Hillary.lum@ucdenver.edu

†Elizabeth Somes and Joanna Dukes contributed equally to this work.

${ }^{3}$ VA Eastern Colorado Geriatric Research Education and Clinical Center, Denver, CO, USA

${ }^{4}$ Division of Geriatric Medicine, University of Colorado School of Medicine, University of Colorado Anschutz Medical Campus, 12631 E. 17th Ave, Mail Stop B179, Aurora, CO 80045, USA

Full list of author information is available at the end of the article
}

(c) The Author(s). 2018 Open Access This article is distributed under the terms of the Creative Commons Attribution 4.0 International License (http://creativecommons.org/licenses/by/4.0/), which permits unrestricted use, distribution, and reproduction in any medium, provided you give appropriate credit to the original author(s) and the source, provide a link to the Creative Commons license, and indicate if changes were made. The Creative Commons Public Domain Dedication waiver (http://creativecommons.org/publicdomain/zero/1.0/) applies to the data made available in this article, unless otherwise stated. 


\section{Background}

Advance care planning is a process that supports adults at any age or stage of health in understanding and sharing their values, goals, and preferences regarding future medical care [1]. Advance care planning is associated with increased hospice use, decreased hospital admissions, reduced medical care costs, and increased patient satisfaction [2, 3]. To increase participation in advance care planning, national recommendations suggest raising public awareness of advance care planning and enabling people to think about future medical care planning in their own life situations [4-6]. One strategy to increase community engagement and promote advance care planning is through non-medical laypersons such as volunteers, community health navigators, and peer educators $[7,8]$.

Trained laypersons have been involved in supporting advance care planning among general older adult populations and specific populations such as ethnic minorities with multiple comorbidities, patients with end-stage renal disease, and patients with cancer [9-11]. These layperson-based programs suggest that individuals value the opportunity to exchange stories with peers who belong to their community group, are a similar age, or share similar experiences [12]. The involvement of volunteers in advance care planning conversations is a natural extension of the long-standing role volunteers have played in interdisciplinary hospice and palliative care teams [13-15].

Laypersons in hospice and palliative care settings serve in multiple capacities, including providing physical, spiritual, and emotional comfort to patients and family caregivers; assisting with information exchange and referral support (e.g., acting as a "bridge to the hospice"); socialization; and companionship [16-19]. Layperson-to-peer communication related to living with serious illness occurs in multiple settings including hospitals and clinics, palliative care programs, hospice programs, and community settings $[7,11,20-22]$. Given the formal and informal involvement of laypersons in communicating with individuals with serious illness, the specific experiences that non-medical laypersons have related to end-of-life communication, including advance care planning conversations, warrants close examination.

Systematic reviews that summarize layperson perspectives on communication related to end-of-life situations are lacking. To address this gap, we performed a meta-synthesis of qualitative studies to address the study question: "What are the perspectives of laypersons on communication with individuals with serious illness or advance care planning?" The intention of this study is to provide a rich description of how trained non-medical laypersons engage in layperson-to-peer conversations related to advance care planning or end of life situations, including palliative care and hospice care.

\section{Methods}

Design

This study is an interpretive thematic synthesis which uses a structured team-based meta-synthesis approach consistent with the ENTREQ standards. Specifically, we extracted salient information about each study, developed descriptive data-driven themes, and then synthesized themes through a process called reciprocal translation [23, 24]. We conducted a comprehensive search to identify articles on non-medical laypersons (i.e., volunteers, patient navigators, peer educators) in communication related to serious illness or advance care planning. We use the term "layperson" to streamline presentation of the results, while acknowledging differences in how various non-medical trained laypersons may be compensated, trained, and integrated into community or healthcare-based programs. We use the term "peer" in recognition that some of individuals that laypersons interacted with were in community-based settings and could be considered a peer, even if they did not personally know them. We also use the term "patient" in recognition that some individuals were in a healthcare context. We chose to perform a meta-synthesis because it provides a mechanism for exploring layperson-to-peer communication across a variety of settings from multiple studies. As a rigorous systematic interpretive study of a defined body of qualitative research, this process produces new knowledge beyond the individual studies and does not include quantitative studies. The analysis involves an integrative synthesis with the following assumptions: 1) the whole published study, not just participant quotations, is treated as qualitative data for interpretation; 2) a multidisciplinary analytic team adds context variation to study interpretation, and 3) when qualitative studies include similar findings, they can be amassed to draw larger and different interpretative meaning $[23,24]$.

\section{Search strategy and study selection}

A comprehensive search was performed by a medical librarian (K.D.) on March 20, 2017. Table 1 summarizes the key search terms used. Relevant publications were identified by searching the following databases: MEDLINE, PsycINFO, CINAHL, Cochrane Library, and AMED. No limiters were used for language or publication date. Publication/source types were limited in PsycINFO and CINAHL to exclude dissertations, theses, and book chapters to improve efficiency of searching and to ensure all included studies had been peer-reviewed and were easily discoverable. Appendix 1 describes the comprehensive search strategies for each database. Reference lists of included studies were hand-searched for additional relevant studies.

The inclusion and exclusion criteria are presented in Table 1. One author (H.L./J.D./A.B.) examined titles for general relevance to the study question of layperson perspectives on communication with individuals with serious 
Table 1 Search strategy and study selection

\begin{tabular}{|c|c|}
\hline Search terms & $\begin{array}{l}\text { 1. Volunteers OR lay navigators OR peer groups } \\
\text { 2. Advance care planning OR advance directives OR palliative care OR hospice } \\
\text { 3. Education OR experience OR sharing OR encouraging } \\
\text { 4. Qualitative methods OR phenomenological study OR focus groups OR grounded } \\
\text { theory OR observation }\end{array}$ \\
\hline Inclusion criteria & $\begin{array}{l}\text { 1. Qualitative methods } \\
\text { 2. Participants are non-medical peers (i.e., volunteer, patient navigator, peer educator } \\
\text { 3. Setting related to advance care planning, palliative care, hospice, or end-of-life }\end{array}$ \\
\hline Exclusion criteria & $\begin{array}{l}\text { 1. Non-English language } \\
\text { 2. Not full papers (i.e., abstracts, posters) } \\
\text { 3. No extractable data from peers } \\
\text { 4. No data relating to communication }\end{array}$ \\
\hline
\end{tabular}

illness or advance care planning. One author (J.D./A.B.) examined study abstracts for relevance, and then two authors (H.L. and J.D.) independently reviewed full studies based on the inclusion and exclusion criteria. The final inclusion of nine studies in the meta-synthesis was confirmed by the study team.

\section{Quality appraisal}

The quality appraisal is an important first step in a meta-synthesis and is a process of immersion into the data. It provides a deeper understanding of each article and helps the team determine the relevance and value of each study toward understanding key findings of the meta-synthesis. To assess study quality (Appendix 2), all articles were independently reviewed using the McMaster University tool [25] by at least two members of an multidisciplinary team including a nurse researcher (U.S.), a palliative care-trained geriatrician (H.L.), and two hospital-based physician researchers (C.J. and K.B.). The tool assesses for the presence or absence of 17 quality domains, including additional subdomains, for a total of 22 items that together address study rigor and other qualitative methodological issues. Any appraisal differences were resolved by consensus and input from another team member (S.J.) who has expertise in qualitative methods. To aid in comparing study quality, each domain received 0 points for No, 1 point for Yes. Not applicable (N/A) ratings were excluded from the total possible score. Scores for each domain were summed and divided by the total possible score (22 minus number of "N/A") multiplied by 100 to provide an overall quality score with a possible range of 0 to $100 \%$. The appraisal was not used to exclude articles.

\section{Meta-synthesis}

Using a meta-synthesis approach based on Thomas and Harden, [24] we extracted study aim, design, methods, type of layperson participants, and main findings of the original studies. Three authors (H.L., J.D., A.B.) reviewed all articles, extracted layperson quotations, and coded meaningful ideas within and across studies. We used an inductive approach for thematic analysis to identify themes and analyze similarities and differences across the studies [24]. In studies with mixed methods, the analysis focused on the qualitative portion of the study. The process was iterative, building consensus through visual mapping of broader domains, themes, and subthemes; naming and renaming; and contextualizing themes through team discussion and re-immersion into the articles to determine whether the emerging results resonated with the original data. Congruent with a meta-synthesis approach, we then used a reciprocal translation approach to create a reciprocal theme table that displayed the synthesized domains and themes alongside themes from the original studies [24]. We maintained an audit trail of decisions and presented and received feedback from multidisciplinary palliative care researchers and clinicians on the derived themes and primary data to contextualize our findings and maintain a high degree of rigor.

\section{Results}

Among 1566 titles identified with the initial search strategy, 690 were duplicates. One additional study was found by hand searching. Of 877 titles screened for general relevance to the study question, 694 titles were removed. Next, 183 abstracts were screened based on the inclusion criteria, and an additional 98 were removed. The full text of 85 articles were assessed, and 76 were excluded (two were not in English, seven were not full studies, 26 did not have discrete qualitative layperson data, and 41 did not address communication). Nine studies remained eligible for inclusion in the meta-synthesis as shown in the PRISMA diagram (Fig. 1) [26].

Table 2 shows study characteristics. Studies were conducted in the United Kingdom (UK) or the United States (US) and published between 2002 and 2017. Most studies used a qualitative descriptive approach with interviews, focus groups, or a combination. Two studies included a participatory action approach and one study used ethnography. Four studies specifically focused on communication related to advance care planning; whereas, five studies addressed the role of laypersons in communicating with 


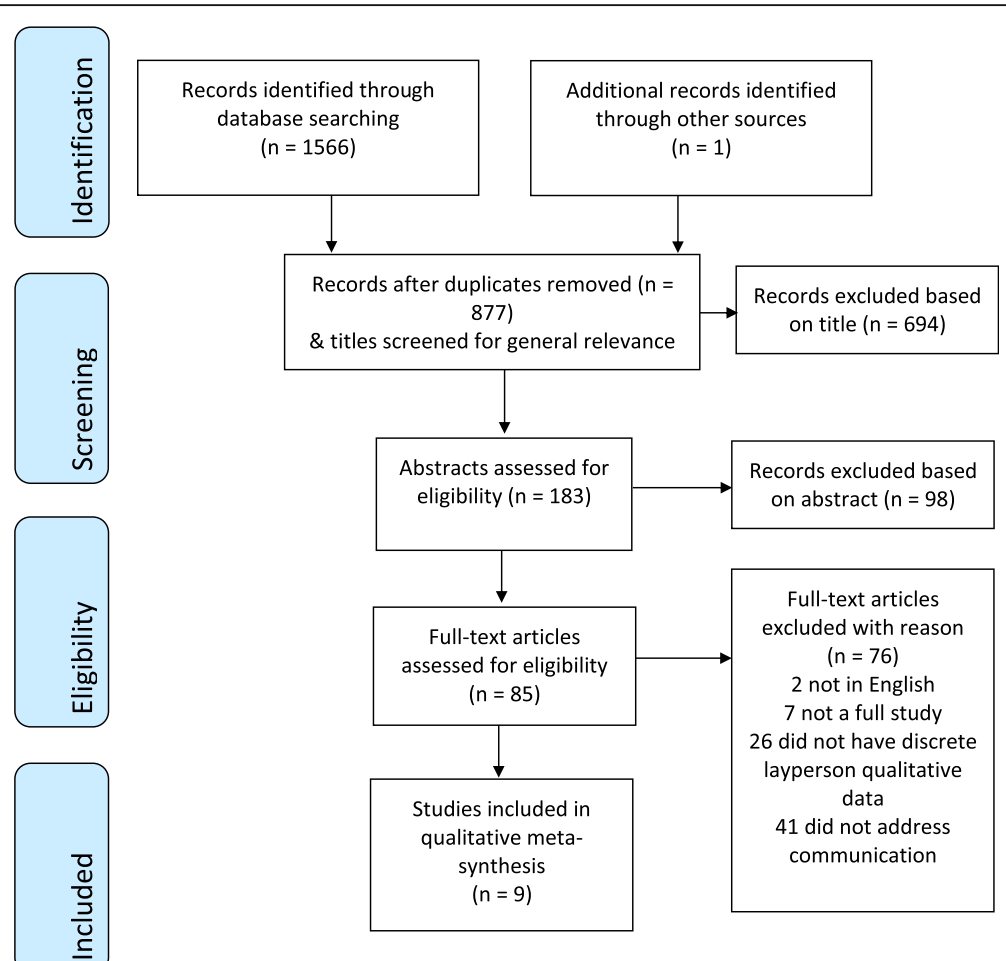

Fig. 1 PRISMA flow diagram

patients who were hospitalized at the end-of-life, had palliative care needs, or were receiving hospice care. Studies included laypersons as volunteers, peer educators, or lay health navigators. Sample sizes ranged from 8 to 351 participants. The combined qualitative data from the nine studies represent a total of 692 laypersons.

In the initial immersion into the data and assessment of study quality, study quality varied with overall quality scores ranging from 50 to $95 \%$ (Appendix 2). Across the nine studies, areas of poor quality were description of sampling methods; description of study site; identification of researchers' biases; and confirmability of data to minimize bias.

\section{Meta-synthesis of themes}

Across nine studies, five major domains with themes and subthemes emerged related to laypersons' involvement in communication related to end-of-life or advance care planning conversations. The major domains were 1) layperson-to-peer communication, focusing on the experience of talking with peers, 2) layperson-to-peer interpersonal interactions, focusing on the entire interaction between the layperson and peers, excluding communication-related issues, 3) personal impact on the layperson, 4) layperson contributions, and 5) layperson training. Figure 2 provides a graphical representation of the domains and associated themes. Table 3 presents each domain, related themes, and subthemes, as well as themes from the original studies to provide additional context.

\section{Layperson-to-peer communication}

The domain of layperson-to-peer communication includes six key themes: a) building rapport, b) talking about sensitive issues, c) listening and allowing silence, d) responding to patient and family emotions, e) communication facilitators, and f) communication barriers. These themes describe the layperson's process of engaging in conversations with a seriously ill peer or initiating advance care planning conversations.

Laypersons focused on building rapport, which included building trust and developing relationships over time. They noted that longitudinal relationships over multiple encounters allowed for time and space to have unhurried discussions about sensitive subject matter. One volunteer described the process as follows,

"You just ... need to hit the ball back over the net when you're talking to someone... who has that disorder. You're not seeking things, you're not negotiating a peace treaty here, and you're not making a business deal here... All you need to do is just hit the ball back over the net. They're gonna hit it right back to you, you just hit it back" [27].

Moreover, laypersons noted that being perceived as a "peer" enhanced trust; "I think she sees me as a friend, also someone to maybe pass on some of her wisdom" [28]. Laypersons often felt most comfortable focusing on life-related subject matter through "life review" conversations.

Layperson-to-peer communication involved talking about sensitive issues, such as advance care planning, 


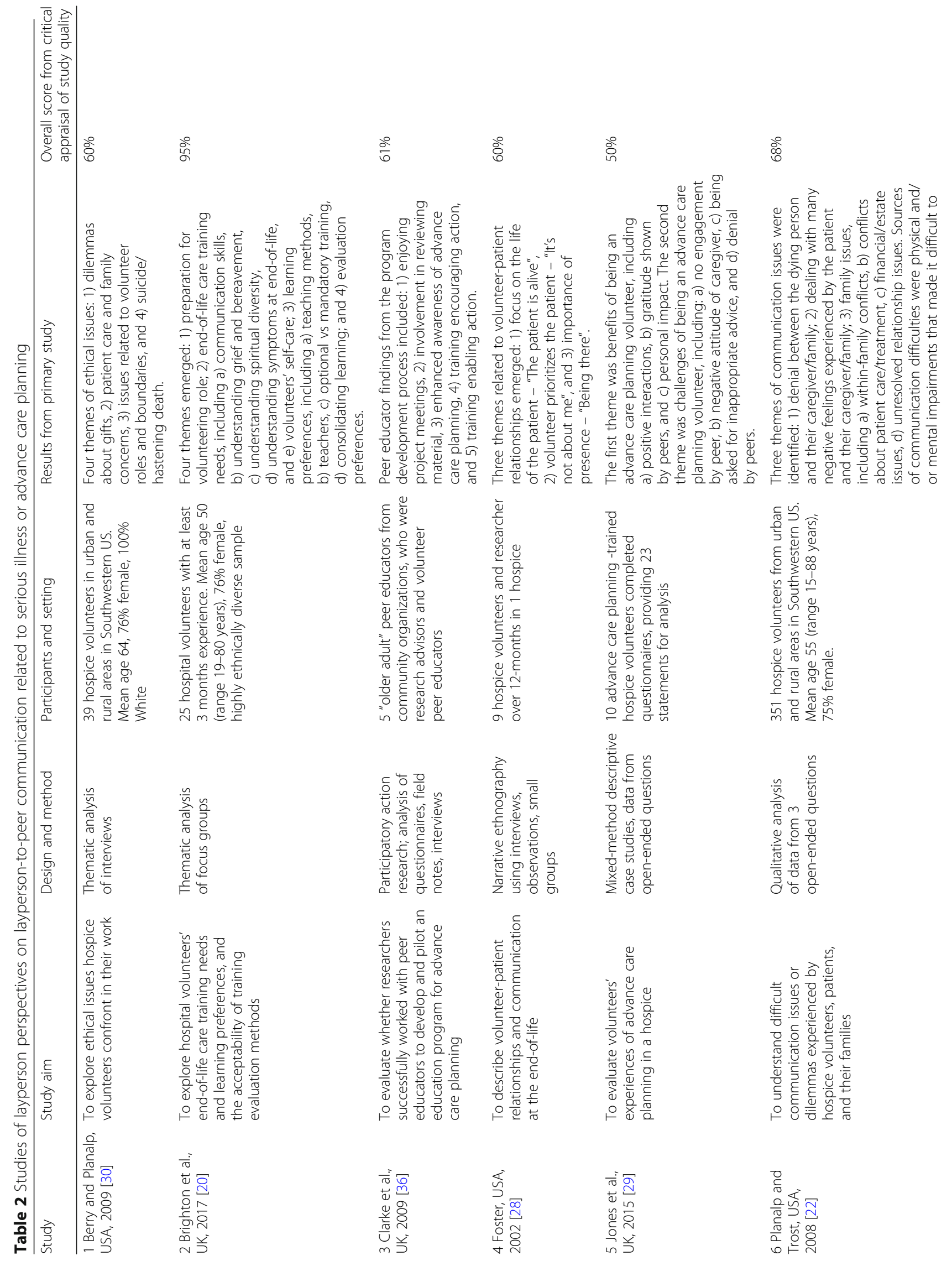




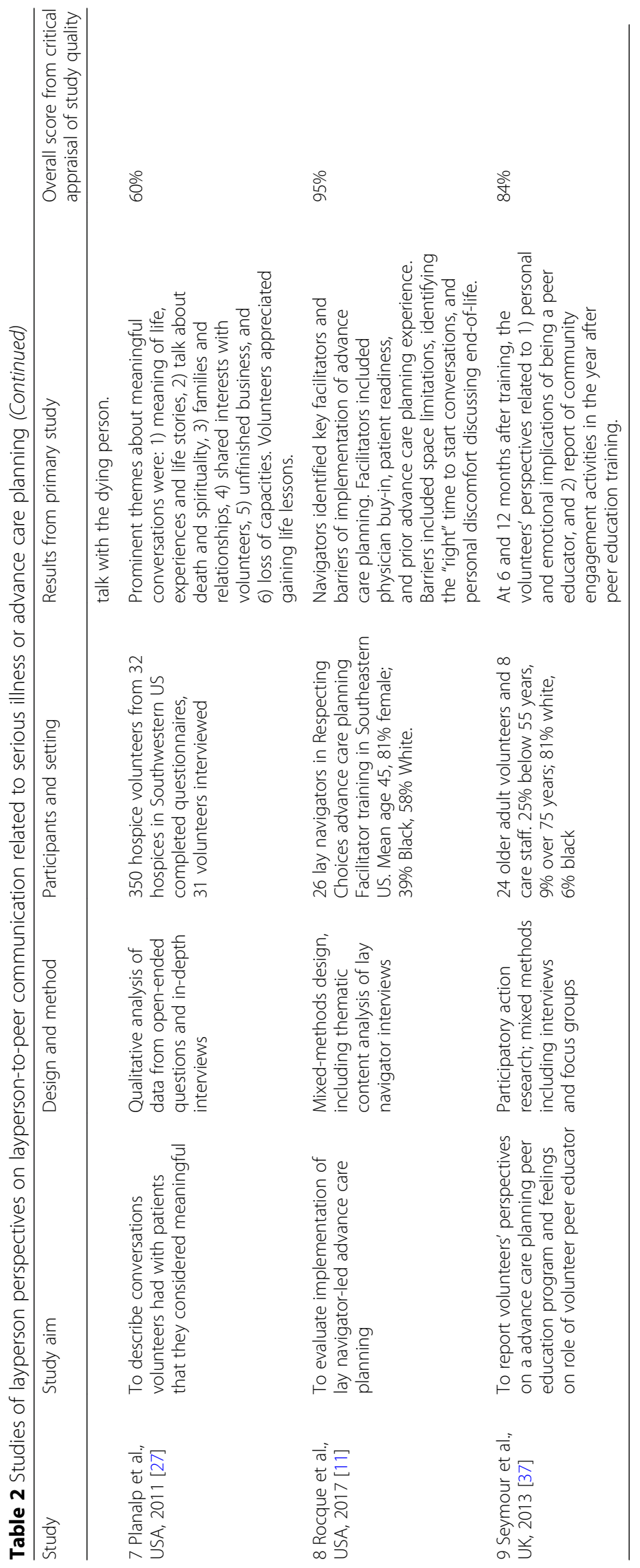




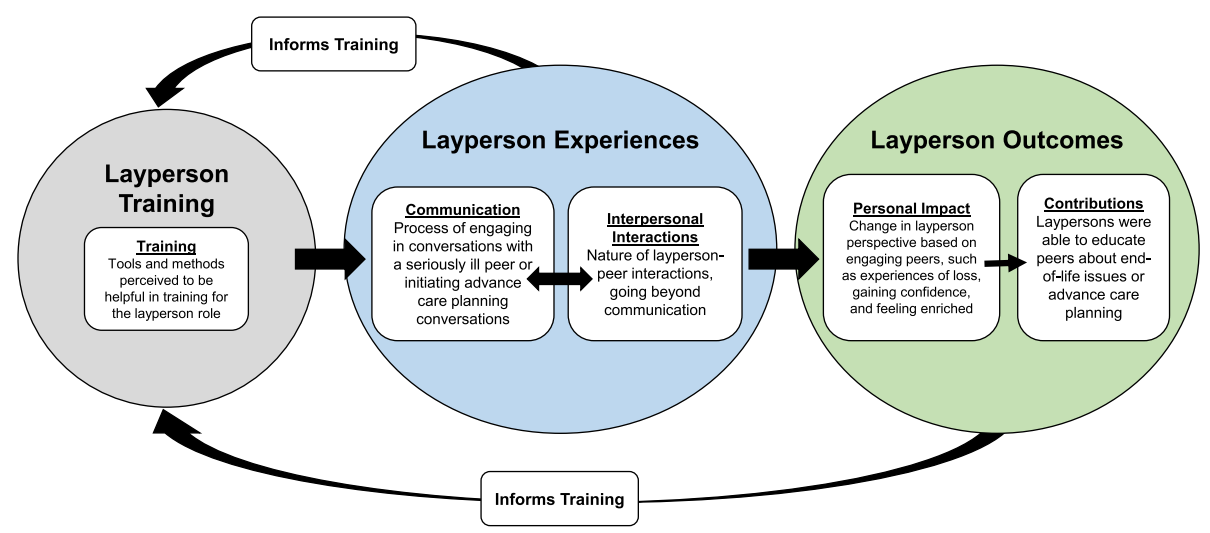

Fig. 2 Layperson perspectives on layperson-to-Peer communication related to training, experiences, and outcomes

prognosis, death, family and caregiver issues, bereavement, and suicide. Laypersons were able to engage in these diverse conversation topics because of their training and by overcoming their own obstacles, such as initial avoidance of death-related subjects and lacking sufficient knowledge of a peer's medical or social situation. When laypersons did initiate difficult conversations with a peer, it was ultimately met with a sense of relief. Through discussions with laypersons, hospice patients and loved ones often overcame denial of death and were able to address end-of-life practicalities, such as funeral planning and care of pets.

Listening and allowing silence was another theme of layperson communication. Some laypersons indicated that silence was anxiety-provoking because initially they worried about their contribution to the conversation and how the patient would perceive them. They reported that over time, they relinquished their self-concern and focused on the patient. They learned that listening, and being present or "in the moment," were the greatest gifts they could give because patients often needed someone to listen without judgement.

Responding to patient and family emotions was another theme of layperson-to-peer communication. Laypersons perceived several negative emotions experienced by patients including fear, anger, regret, guilt, loss of dignity, and feeling like a burden to their families. Laypersons also described that families appeared to experience grief, fatigue, discouragement, feeling trapped, and feeling guilty for wanting the process to be over. Families were fearful of losing their loved one, fearful of not being present at the time of death, and concerned about the loved one's pain and not being able to alleviate it. Laypersons wanted to learn how to sensitively and appropriately respond to these emotions.

Laypersons identified communication facilitators of layperson-to-peer communication, including physician endorsement and healthcare team involvement. For example, they felt that physician endorsement of layperson-led advance care planning conversations would help to reinforce its importance. They also felt that the support and involvement of healthcare team members helped when a patient's questions surpassed the layperson's role. One volunteer noted,

"If they start askin' questions that I'm not sure of, then I'll get a nurse. I'll ask her questions, and I'll come back to 'em. I've had one that would ask about, well, how long would they keep feeding me before they would turn me off or whatever...I wasn't sure, so I went and got an MD to answer the question for me" [11].

Laypersons also identified several communication barriers. Laypersons noted peer-related obstacles to conversations, including denial of death, lack of readiness, limited health literacy, and family conflicts. Specific barriers included physical or cognitive impairments, such as Parkinson's disease or dementia, or the active dying process. In these situations, non-verbal communication became even more important when a patient's disease made verbal communication difficult. Patients seemed to be reassured by the layperson's presence. Specific to advance care planning conversations, laypersons noted health literacy limitations, including how the peers they were supporting seemed overwhelmed by medical information and jargon provided by the healthcare teams. At the broader community or healthcare system-level, a lack of time and space for advance care planning conversations, lack of widespread healthcare provider support, and cultural suspicion about talking about death and dying were the primary communication barriers. A volunteer in an advance care planning program stated, "I found it stressful with the pressure of completing an advance care planning quickly. It was like hitting a target" [29].

\section{Layperson-to-peer interpersonal interactions}

The second domain describes the nature of the layperson-to-peer interactions, going beyond communication. The themes included: a) discomfort with the peer's situation, 


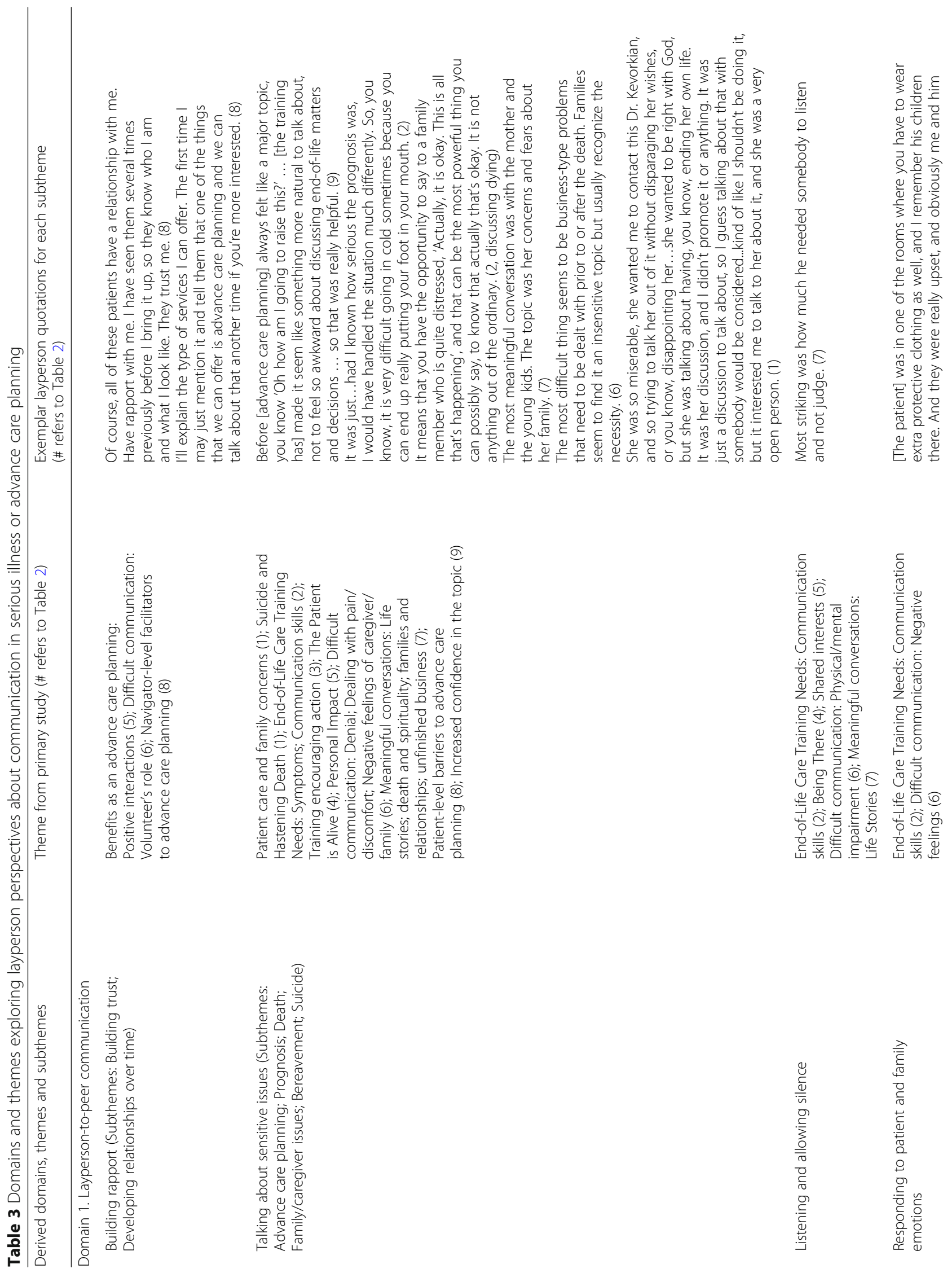




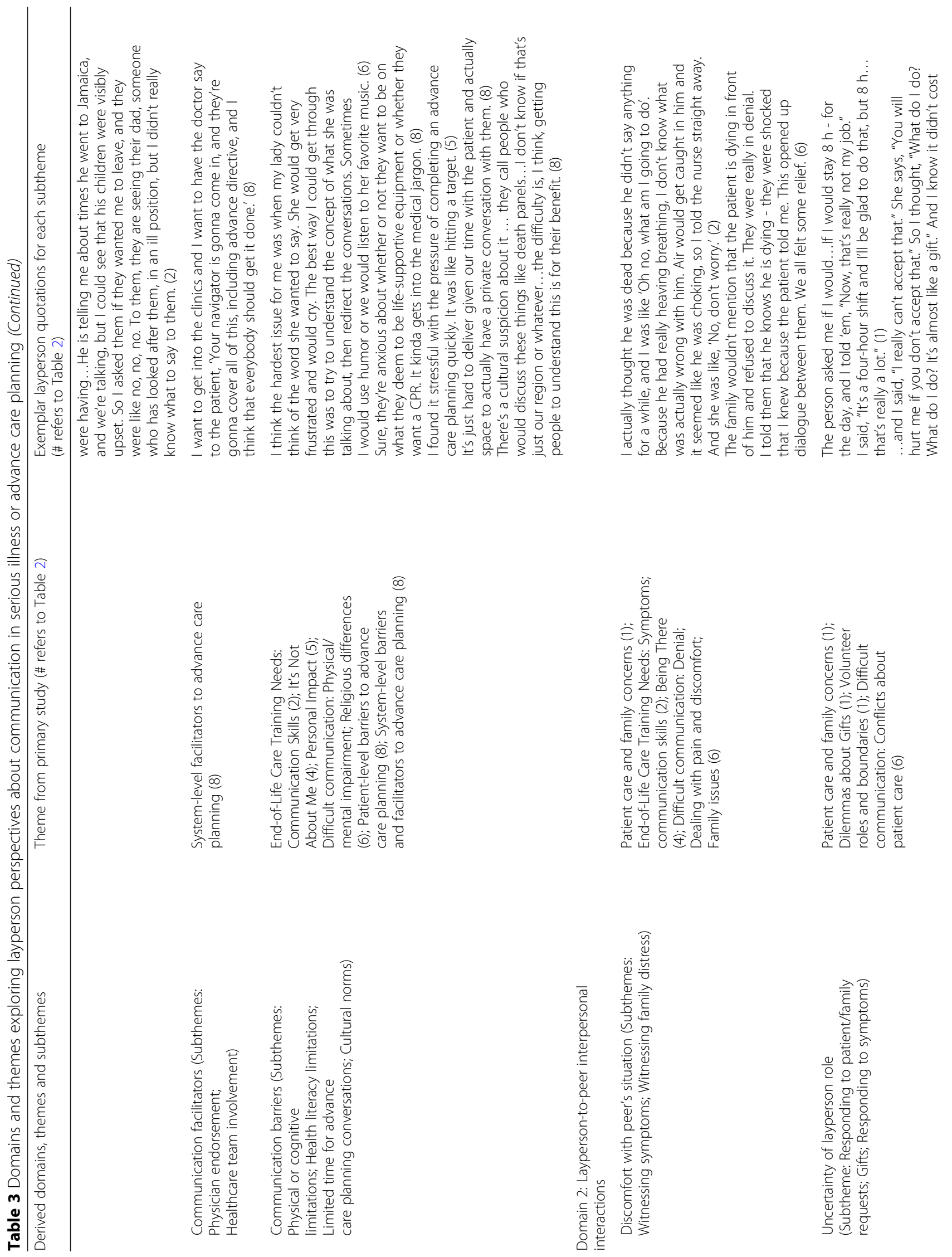




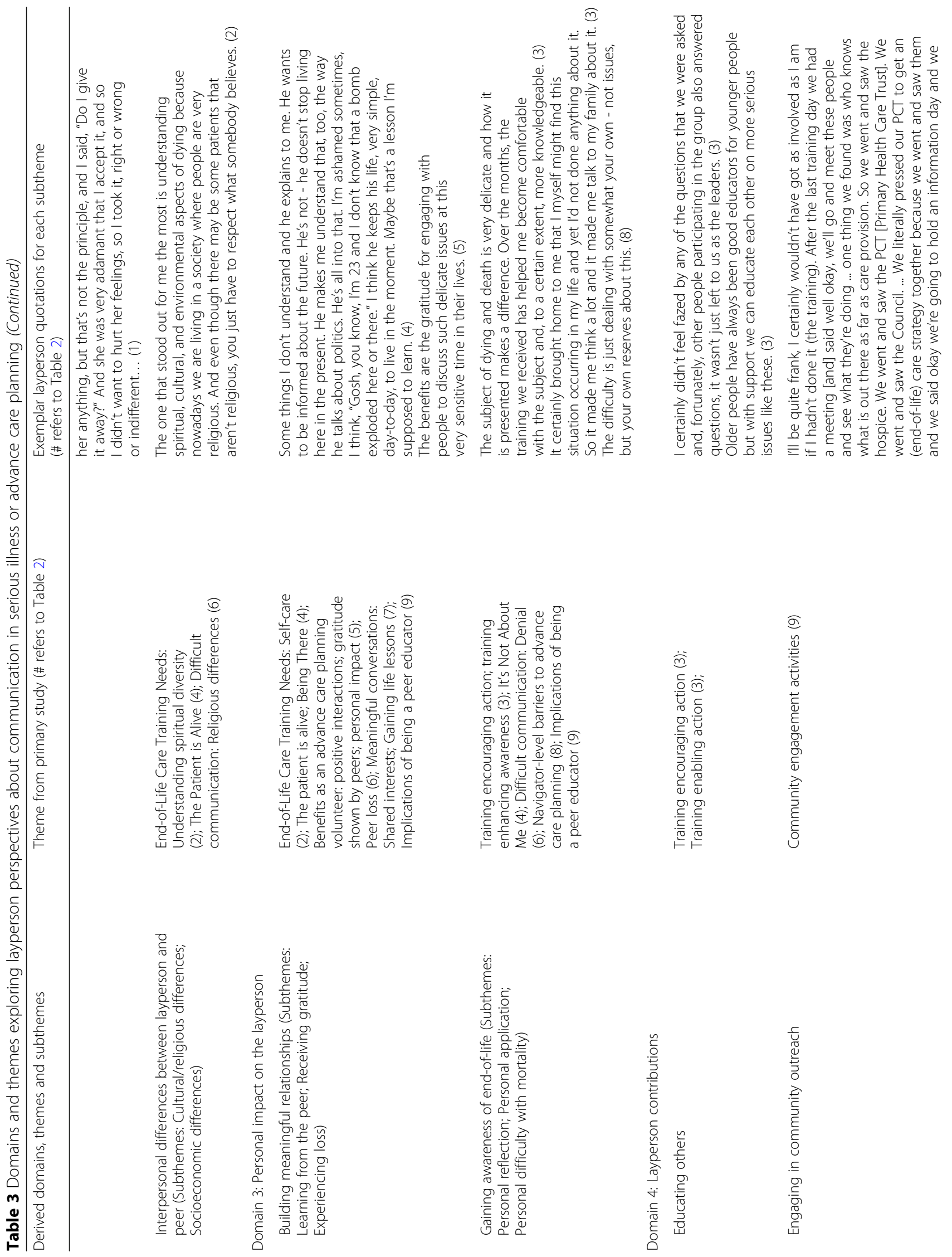




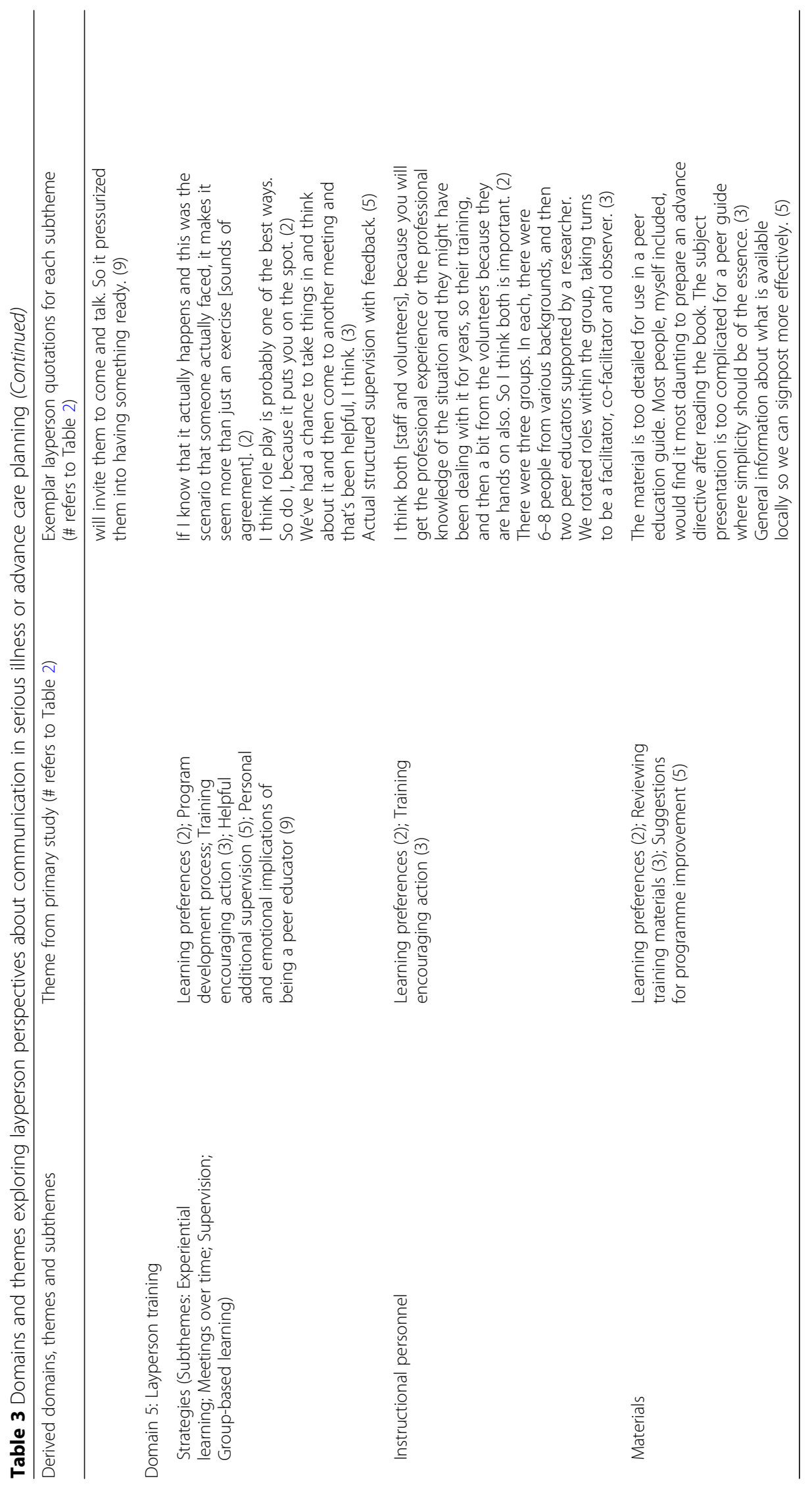


b) uncertainty of the layperson role, and c) interpersonal differences between layperson and peer. Discomfort with the peer's situation encompassed witnessing symptoms and witnessing family distress. Laypersons described feeling helpless when observing patients' symptoms and not knowing what to do. Some were upset when witnessing a patient's distress over not being able to communicate, and felt unsure of how to help a patient with dementia. Witnessing a patient's or family's denial about death, hurtful family interactions, or emotional distress also caused discomfort. Laypersons identified these circumstances as opportunities for further training and desired clear preparation for encounters with distress, the dying process, and death.

A second theme that characterized interpersonal interactions was laypersons' uncertainty of their role. This theme included uncertainty regarding responding to patient/family requests, gifts, and responding to symptoms. A commonly cited reason for this uncertainty was the position of being neither friend nor provider. Laypersons felt that they were in a nebulous in-between role. One volunteer described:

"[The patient] was in pain, and made it very clear that he wanted his morphine, which is an absolute...you know, no-no. I'm not supposed to be dispensing medication. It was, for me, a very uncomfortable and difficult situation to be in, 'cause on the one hand, you don't want to watch a human being suffer. On the other hand, it was made very clear to me that, you know, 'this is something you don't do!"' [30].

Laypersons recounted requests from patients and families that were inappropriate for this in-between role, such as dispensing pain medications, staying at the facility beyond their volunteer shift, or performing conspiratorial favors, such as throwing away an item that the patient didn't want his family to see. This nebulous role also meant receiving gifts put them in an awkward position. If the layperson was a personal friend, they would have no problem receiving gifts. If they were a healthcare team member, they would have clear boundaries for declining gifts. Laypersons' uncertainty also related to responding to symptoms or the peer's self-care needs. They were uncertain about their role when advocating for the patient when concerns about a patient's care or needs were raised. Laypersons often needed to navigate their role with the peer, family members, and healthcare team members, each of whom may have had different expectations of the layperson's role and appropriate level of involvement.

Interpersonal differences between layperson and peer was a third theme and included the subthemes of cultural or religious differences and socioeconomic differences. Some laypersons perceived that religious differences could be a barrier. For example, some laypersons described feeling disconnected from a peer whose beliefs contradicted their own, while others admitted it was difficult to refrain from sharing their own beliefs. Awareness of these differences, however, did not necessarily cause a rift between the layperson and peer. One layperson recalled a patient with whom she connected despite their very different socioeconomic backgrounds:

"We instantly connected because we left out all the bullshit and just connected on a human level. And there's a lot of female connection that we have, too. We connect as two women. We can talk about men, our husbands, what society expects of us as women, and what we want out of life. So she, I realized, shares the dreams and desires and aspirations that I have. We're sisters under the skin" [28].

\section{Personal impact on the layperson}

The third domain is the personal impact on the layperson as they engaged in training, meeting peers with serious illness, or initiating advance care planning conversations. A key theme of this domain was building meaningful relationships, including learning from the peer, receiving gratitude, and experiencing loss. Laypersons describe "enriching" and "rewarding" experiences, gleaning wisdom from their patient as a "living history." They felt rewarded by gratitude from the patient, which they felt accounted for the challenges of discussing death and dying. By forming strong connections with patients, however, they also experienced loss. Laypersons commented on the difficulty of letting go of friendships that had formed, stating:

"It does affect you at times when you know someone, you may be seeing them... [and] during two or three weeks you get to know them, and then they are gone" [20].

Personal impact on the layperson also included gaining awareness of end-of-life. Laypersons elaborated on this awareness in subthemes of personal reflection, personal application, and personal difficulty with mortality. Several laypersons commented that death became less daunting as a result of their experiences, especially when seen through the eyes of a peer with a positive outlook. They gained a better appreciation of how others approach end-of-life issues, and a deeper understanding of loss. They applied these lessons to their own lives, feeling better prepared to support those who had lost someone and how to advocate for their own wishes. One layperson commented that his experience had been a "re-education," and he had become more compassionate as a result. Not all experiences were positive. Some laypersons discussed their own anxieties about mortality limited their ability to help patients.

\section{Layperson contributions}

The fourth domain is layperson contributions and includes the themes of educating others and engaging in community outreach. Through effective training programs, laypersons discovered that they were able to educate their 
peers about end-of-life issues or advance care planning. They felt satisfaction when seeing the results of their hard work, such as completing a workbook for advance care planning with a peer. Some felt emboldened to engage their own families in end-of-life care discussions and even expanded their work into the wider community. For example, some trained peer educators hosted information sessions and meetings with local community stakeholders. They became further involved in local and national organizations aimed at increasing awareness of death and advance care planning.

\section{Layperson training}

The final domain is layperson training. Several studies described the processes of preparing laypersons to be peer navigators, educators, or hospice or hospital-based volunteers to support individuals with serious illnesses or to initiate advance care planning conversations. Layperson training focused on communication skills and provided laypersons with knowledge, experience, and confidence to address specific communication issues, as well as the broader role of supporting a peer. In addition to the content-focused suggestions that laypersons had related to the aforementioned domains, layperson input specific to training included strategies, instructional personnel, and materials. Suggestions for training strategies included experiential learning, meetings over time, supervision, and group-based learning. Laypersons preferred experiential learning, using real case examples and role playing, over computer-based "e-learning" or virtual classrooms. In terms of timing, they valued attending trainings that continued after starting the layperson role because they were able to learn from their real-life experiences, reflect between sessions, and receive on-going support from other laypersons. Structured supervision with feedback was another training need. Lastly, laypersons felt co-leading a group discussion related to advance care planning, rather than independently leading groups, helped peer education to go more smoothly.

A second theme related to layperson training was instructional personnel. Laypersons found that the most effective training was provided by experienced lay volunteers and healthcare professionals (e.g., palliative care providers), in addition to the program coordinators. The third training suggestion related to materials. Laypersons felt that simpler, more layperson-friendly materials were more effective than advance care planning printed materials that used complicated jargon. They also suggested that advance care planning materials for peers be based on stories or examples to make the concepts more understandable.

\section{Discussion}

\section{Main findings of the study}

This meta-synthesis addresses the study question: "What are the perspectives of laypersons on communication with individuals with serious illness or advance care planning?" We provide an integrated synthesis of the thoughts and experiences of non-medical laypersons as they communicate with peers experiencing serious illnesses, end-of-life care, or related to advance care planning conversations. In focusing on layperson-to-peer communication, this analysis describes commonalities in how trained laypersons approached and experienced conversations. It also highlights the variety of interactions, social or clinical context, benefits, and challenges of those conversations. The findings provide additional support to the role of laypersons in having meaningful conversations, though healthcare provider or physician endorsement of the layperson role may improve their effectiveness $[8,14]$. Together with specific input from laypersons on their training needs, these findings can inform best practices for training and ongoing support systems for community or healthcare system-based programs that involve lay individuals. The synthesized results provide a foundation for the design and adaptation of peer-based programs that focus on communication skills and training.

This study offers insight into the benefits and challenges of laypersons' engagement in advance care planning conversations. While other research studies focus on advance directive documentation, this study describes how engaging with seriously ill patients or peers in advance care planning conversations can be a challenging yet rewarding experience from the layperson's perspective [31]. A future analysis should also include perspectives of the peer/patient and family caregivers [32]. Laypersons also shared similar sentiments regarding end-of-life communication: being with the patient and his/her loved ones and talking about death could be anxiety-provoking or uncomfortable, especially with inadequate training. Many laypersons and patients still found the experience to be positive. Laypersons specifically described increased awareness of end-of-life issues for themselves and, in turn, initiated conversations with families, friends, and sometimes their broader community. Thus, the investment of training a layperson for involvement in palliative care, hospice, or other programs to support seriously ill individuals may yield community-level benefits related to discussions about death and dying. Additionally, for programs that utilize older adult volunteers, this analysis aligns with a theoretical benefit between volunteering and successful aging through opportunities for communication [33, 34].

As a meta-synthesis, this study included individual studies that involved laypersons in highly varied settings, including hospices, hospitals, and community-based outreach programs to enhance advance care planning conversations. There were diverse types of non-health laypersons, including hospital volunteers, hospice volunteers, lay health navigators, and peer educators. The 
laypersons may have been part of a specific communication-based program or may have had opportunities for communication as part of their broader role. Although this meta-synthesis provides access to context variation within and across studies, the application of the key findings must be re-contextualized to the particular type of layperson, type of peer/patient, and program implementation setting. The laypersons' suggestions on training, planning for program sustainability, and legal and ethical aspects of the involvement of laypersons in communication-based roles need to be adapted to regional or national policy considerations. The unique position of laypersons may require training measures specific to them because laypersons experienced uncertainty in their role, being neither a caregiver nor a health care professional. However, laypersons reported building and using communication skills such as building rapport, responding to patient and family emotions, and talking about sensitive issues which are skills also used by health care professionals. Because these skills are commonly used by health and social care professionals, there may be opportunities to adapt existing training models for use in layperson programs. Additionally, further study could evaluate the potential benefit and challenges of shared training, at least in part, for health care providers and laypersons in communication skills for a particular program. Given the significant difference in the role of a healthcare provider and a trained layperson, skills which may seem transferable between the two may still require different training methods and would require further evaluation.

Further research on the impact of laypersons in advance care planning or end-of-life conversations is warranted. This meta-synthesis focuses on the perspectives of laypersons, but future work should focus on the perspectives of patients, family members, and members of the healthcare team regarding the role and impact of laypersons. Prior to widespread adoption of laypersons in this role, specific evaluation of the safety and potential effectiveness of trained laypersons on communication and other meaningful person-centered outcomes is needed.

\section{Limitations of the study}

This study has several limitations. As a meta-synthesis, we did not have access to the original data sets, including complete transcripts or field notes, and were limited in our ability to interpret the linguistic and cultural context of the published quotations. Additionally, the focus on qualitative studies, inclusion criteria, and exclusion criteria resulted in unintentionally limiting the geographical location of the studies to the US and the UK. For example, in choosing to exclude grey literature such as dissertations, theses, and book chapters, we may have biased the findings toward established programs that had desire and ability to publish in peer-reviewed journals. The literature search yielded studies involving laypersons in palliative care or end-of-life settings conducted elsewhere, such as Canada and Uganda, but those studies did not specifically examine communication or use qualitative methods $[18,35]$. Still, the majority of studies relating to volunteer or other layperson experiences are based in the US, Canada, or UK, making it difficult to broadly apply the findings of this meta-synthesis beyond these regions. Future work should include grey literature as this literature may have insights from additional settings, making the results of a meta-synthesis more broadly applicable. Additionally, the scope of this study did not include quantitative outcomes related to advance care planning programs involving trained laypersons [31]. An additional limitation to the study is that there was no layperson on the research team contributing to the analysis of themes.

\section{Conclusions}

The findings from layperson perspectives on communication with peers experiencing serious illness or related to advance care planning have practical implications. Since volunteers are more likely to commit to an activity that is personally satisfying, volunteer laypersons may constitute a reliable and cost-effective way to enhance advance care planning efforts and support individuals with palliative care needs, especially in community-based settings [35]. Training, and even paying, laypersons could be a viable alternative to training existing healthcare providers in specific advance care planning communication skills, especially in resource-limited settings. Moreover, because laypersons may have more time or common life factors on which to establish rapport, laypersons are uniquely positioned to engage in end-of-life conversations with peers experiencing serious illnesses.

In conclusion, we synthesized the perspectives of a diverse group of laypersons who were involved in communicating with individuals with serious illnesses or as part of advance care planning programs. Together the studies described the involvement of laypersons in meaningful conversations with their peers and outlined interpersonal interactions, personal impact, contributions, and training that laypersons experienced. Laypersons may complement and potentially enhance the work of healthcare providers in meeting the educational and psychosocial needs of individuals and their family caregivers in palliative care settings. Programs that involve laypersons should include training specifically for layperson-to-peer conversations related to the end-of-life period, as well as a mechanism for 


\section{Appendix 1}

Table 4 Search strategies. Comprehensive search strategies used to identify articles for each database

MEDLINE, including Ovid MEDLINE Epub Ahead of Print, In-Process \& Other Non-Indexed Citations, and Ovid MEDLINE Daily (1946-present)

PsycINFO via Ovid

(1806 to March Week 2 2017)

CINAHL Cumulative Index to Nursing and Allied Health Literature (CINAHL) via EBSCOhost (exp Peer Group/ or exp. Volunteers/ or exp. Mentors/ or exp.

Patient Navigation/ or (voluntary or peer* or volunteer* or mentor*

or navigator* or lay*).tw,kf.) and (exp Advance Care Planning/ or exp.

Hospices/ or exp. Hospice and Palliative Care Nursing/ or exp. Palliative

Medicine/ or exp. Palliative Care/ or exp. Terminal Care/ or (Living Will*

or Medical Power* Attorney or Health Care Power* Attorney or

Healthcare Power* Attorney or advance* care plan* or advance*

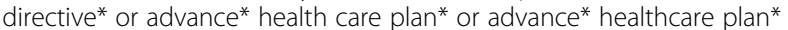

or advance* medical plan* or hospice* or palliative or terminal care or end-of-life).tw,kf.) and (exp Patient Education as Topic/ or exp.

Counseling/or exp. Information Dissemination/ or exp. Teaching/ or exp. Consumer Health Information/ or (discussion* or coaching or navigation* or navigating or learning or awareness or training or conversation* or engag* or promotion* or story or stories or experienc* or sharing or educator* or education* or educating or encourag* or teaching or counseling or information or knowledge or communicat*).tw,kf.) and (exp Qualitative Research/ or exp. Grounded Theory/ or exp. Interviews as Topic/ or exp. Focus Groups/ or exp. Nursing Methodology Research/ or exp. anecdotes as topic/ or exp. narration/ or exp. "surveys and questionnaires"/ or exp. personal narratives as topic/ or exp. Observational Studies as Topic/ or exp. interview/ or exp. personal narratives/ or exp. observational study/ or (qualitative or ethnograph* or phenomenol* or grounded theor* or purposive sampl* or hermeneutic* or heuristic* or semiotics or lived experience* or narrat* or life experience* or cluster sample* or action research or observational method* or content analys* or thematic analys* or constant comparative method* or field stud* or theoretical sampl* or discourse analys* or focus group* or ethnological research or ethnomethodolog* or interview* or mixed method* or mixed model* or mixed design* or survey* or questionnaire* or anecdote*).tw,kf.)

(exp peers/ or exp. volunteers/ or mentor/ or (voluntary or peer* or volunteer* or mentor* or navigator* or lay*).ab,ti.) and (exp advance directives/ or exp. Palliative Care/ or exp. hospice/ or (Living Will* or Medical Power* Attorney or Health Care Power* Attorney or Healthcare Power* Attorney or advance* care plan* or advance* directive* or advance* health care plan* or advance* healthcare plan* or advance* medical plan* or hospice* or palliative or terminal care or end-of-life).ab,ti.) and (exp peer education/ or exp. Community Counseling/ or exp. Educational Counseling/ or exp. Peer Counseling/ or exp. information dissemination/ or exp. teaching/ or exp. consumer education/ or exp. death education/ or (discussion* or coaching or navigation* or navigating or learning or awareness or training or conversation* or engag* or promotion* or story or stories or experienc* or sharing or educator* or education* or educating or encourag* or teaching or counseling or information or knowledge or communicat*).ab,ti.) and (exp qualitative research/ or exp. grounded theory/ or exp. Interviews/ or exp. Narratives/ or exp. surveys/ or exp. questionnaires/ or exp. narratives/ or (qualitative or ethnograph* or phenomenol* or grounded theor* or purposive sampl* or hermeneutic* or heuristic* or semiotics or lived experience* or narrat* or life experience* or cluster sample* or action research or observational method* or content analys* or thematic analys* or constant comparative method* or field stud* or theoretical sampl* or discourse analys* or focus group* or ethnological research or ethnomethodolog* or interview* or mixed method* or mixed model* or mixed design* or survey* or questionnaire* or anecdote*).ab,ti.) Publication types were limited to ("0100 journal" or "0110 peer-reviewed journal" or "0120 non-peer-reviewed journal" or "0130 peer-reviewed status unknown").

(MH "Peer Group" OR MH "Volunteer Workers" OR MH "Volunteer Experiences" OR TI (voluntary or peer* or volunteer* or mentor* or navigator* or lay*) OR $\mathrm{AB}$ (voluntary or peer* or volunteer* or mentor* or navigator* or lay*)) AND (MH "Advance Care Planning" OR MH "Advance Directivest" OR MH "Hospice Patients" OR MH "Hospice and Palliative Nursing" OR MH "Hospices" OR MH "Terminal Care+" OR MH "Palliative Care" OR TI (Living Will* or Medical Power* Attorney or Health Care Power* Attorney or Healthcare Power* Attorney or advance* care plan* or advance* directive* or advance* health care plan* or advance* healthcare plan* or advance* medical plan* or hospice* or palliative or terminal care or end-of-life) OR AB (Living Will* or Medical Power* Attorney or Health Care Power* Attorney or Healthcare Power* Attorney or advance* care plan* or advance* directive* or advance* health care plan* or advance* healthcare plan* or advance* medical plan* or hospice* or palliative or terminal care or end-of-life)) AND (MH "Patient Education+" OR MH "Counseling+" OR MH "Teaching" OR MH "Death Education" OR MH "Consumer Health Information+"
Results

Results 
Table 4 Search strategies. Comprehensive search strategies used to identify articles for each database (Continued)

Cochrane Library (via Wiley, including Cochrane Database of Systematic Reviews, Database of Abstracts of Reviews of Effect, Cochrane Central Register of Controlled Trials, Cochrane Methodology Register, Health Technology Assessment Database, and NHS Economic Evaluation Database)
OR TI (discussion* or coaching or navigation* or navigating or learning or awareness or training or conversation* or engag* or promotion* or story or stories or experienc* or sharing or educator* or education* or educating or encourag* or teaching or counseling or information or knowledge or communicat*) OR AB (discussion* or coaching or navigation* or navigating or learning or awareness or training or conversation* or engag* or promotion* or story or stories or experienc* or sharing or educator* or education* or educating or encourag* or teaching or counseling or information or knowledge or communicat*)) AND (MH "Qualitative Studies+" OR MH "Ethnological Research" OR MH "Action Research" OR MH "Phenomenological Research" OR MH "Ethnographic Research" OR MH "Field Studies" OR MH "Grounded Theory" OR MH "Multimethod Studies" OR MH "Survey Research" OR MH "Phenomenology" OR MH "Focus Groups" OR MH "Interviewst" OR MH "Narratives" OR MH "Surveyst" OR MH "Observational Methodst" OR MH "Discourse Analysis" OR MH "Thematic Analysis" OR MH "Content Analysis" OR MH "Qualitative Validity+" OR TI (qualitative or ethnograph* or phenomenol* or grounded theor* or purposive sampl* or hermeneutic* or heuristic* or semiotics or lived experience* or narrat* or life experience* or cluster sample* or action research or observational method* or content analys* or thematic analys* or constant comparative method* or field stud* or theoretical sampl* or discourse analys* or focus group* or ethnological research or ethnomethodolog* or interview* or mixed method* or mixed model* or mixed design* or survey* or questionnaire* or anecdote*) OR AB (qualitative or ethnograph* or phenomenol* or grounded theor ${ }^{*}$ or purposive sampl* or hermeneutic* or heuristic* or semiotics or lived experience* or narrat* or life experience* or cluster sample* or action research or observational method* or content analys* or thematic analys* or constant comparative method* or field stud* or theoretical sampl* or discourse analys* or focus group* or ethnological research or ethnomethodolog* or interview* or mixed method* or mixed model* or mixed design* or survey* or questionnaire* or anecdote*)) Dissertation/thesis was excluded as a source type.

$\# 1 \rightarrow$ MeSH descriptor: [Peer Group] explode all trees

Results $\# 2 \rightarrow$ MeSH descriptor: [Volunteers] explode all trees

$\rightarrow$ MeSH descriptor: [Mentors] explode all trees

$\# 4 \rightarrow$ MeSH descriptor: [Patient Navigation] explode all trees

$\# 5 \rightarrow$ voluntary or peer or volunteer or mentor or navigator or lay:ti orab orkw (Word variations have been searched)

$\# 6 \rightarrow$ MeSH descriptor: [Advance Care Planning] explode all trees

$\# 7 \rightarrow$ MeSH descriptor: [Hospices] explode all trees

$\# 8 \rightarrow$ MeSH descriptor: [Hospice and Palliative Care Nursing] explode all trees

$\# 9 \rightarrow$ MeSH descriptor: [Palliative Medicine] explode all trees

$\# 10 \rightarrow$ MeSH descriptor: [Palliative Care] explode all trees

$\# 11 \rightarrow$ MeSH descriptor: Terminal Care] explode all trees

$\# 12 \rightarrow$ "Living Will" or "Medical Power of Attorney" or "Health Care Power Attorney" or "Healthcare Power of Attorney" or "advance care planning" or "advance directive" or "advance health care plan" or "advance healthcare plan" or "advance medical plan" or hospice or palliative or "terminal care" or "end of life".ti orab orkw (Word variations have been searched)

$\# 13 \rightarrow$ MeSH descriptor: [Patient Education as Topic] explode all trees

$\# 14 \rightarrow$ MeSH descriptor: [Counseling] explode all trees

$\# 15 \rightarrow$ MeSH descriptor: [Information Dissemination] explode all trees

$\# 16 \rightarrow \mathrm{MeSH}$ descriptor: [Teaching] explode all trees

$\# 17 \rightarrow$ MeSH descriptor: [Consumer Health Information] explode all trees

$\# 18 \rightarrow$ discussion or coaching or navigation or navigating or learning or awareness or training or conversation or engagement or promotion or story or stories or experience or sharing or educator or education or educating or encouragement or teaching or counseling or information or knowledge or communication:ti orab orkw (Word variations have been searched)

$\# 19 \rightarrow$ MeSH descriptor: [Qualitative Research] explode all trees

$\# 20 \rightarrow$ MeSH descriptor: [Grounded Theory] explode all trees

$\# 21 \rightarrow$ MeSH descriptor: [Interviews as Topic] explode all trees

$\# 22 \rightarrow$ MeSH descriptor: [Focus Groups] explode all trees

\#23 $\rightarrow$ MeSH descriptor: [Nursing Methodology Research] explode all trees

$\# 24 \rightarrow$ MeSH descriptor: [Anecdotes as Topic] explode all trees

\#25 $\rightarrow$ MeSH descriptor: [Narration] explode all trees

$\# 26 \rightarrow$ MeSH descriptor: [Surveys and Questionnaires] explode all trees

$\# 27 \rightarrow$ MeSH descriptor: [Personal Narratives as Topic] explode all trees

$\# 28 \rightarrow$ MeSH descriptor: [Observational Studies as Topic] explode all trees

$\# 29 \rightarrow$ MeSH descriptor: [Interview] explode all trees

$\# 30 \rightarrow$ MeSH descriptor: [Personal Narratives] explode all trees 
Table 4 Search strategies. Comprehensive search strategies used to identify articles for each database (Continued)

Allied and Complementary Medicine (AMED) via Ovid (1985 to March 2017)

$$
\begin{aligned}
& \# 31 \rightarrow \text { MeSH descriptor: [Observational Study] explode all trees } \\
& \# 32 \rightarrow \text { qualitative or ethnography or phenomenoly or } \\
& \text { "grounded theory" or "purposive sample" or hermeneutics or } \\
& \text { heuristics or semiotics or "lived experience" or narrative or } \\
& \text { "life experience" or "cluster sample" or "action research" or } \\
& \text { "observational method" or "content analysis" or "thematic analysis" } \\
& \text { or "constant comparative method" or "field study" or "theoretical } \\
& \text { sample" or "discourse analysis" or "focus group" or "ethnological } \\
& \text { research" or ethnomethodology or interview or "mixed method" } \\
& \text { or "mixed model" or "mixed design" or survey or questionnaire } \\
& \text { or anecdote:ti,ab,kw (Word variations have been searched) } \\
& \# 33 \rightarrow \text { (\#1 or \#2 or \#3 or \#4 or \#5) and (\#6 or \#7 or \#8 or \#9 or \#10 } \\
& \text { or \#11 or \#12) and (\#13 or \#14 or \#15 or \#16 or \#17 or \#18) and } \\
& \text { (\#19 or \#20 or \#21 or \#22 or \#23 or \#24 or \#25 or \#26 or \#27 or \#28 } \\
& \text { or \#29 or \#30 or \#31 or \#32) }
\end{aligned}
$$

(exp Peer group/ or exp. Voluntary workers/ or exp. Mentors/ or (voluntary or peer* or volunteer* or mentor* or navigator* or lay*).ab,ti.)

AND (exp advance directives/ or exp. hospices/ or exp. palliative care/ or exp. terminal care/ or (Living Will* or Medical Power* Attorney or Health Care Power* Attorney or Healthcare Power* Attorney or advance* care plan* or advance* directive* or advance* health care plan* or advance* healthcare plan* or advance* medical plan* or hospice* or palliative or terminal care or end-of-life).ab,ti.) AND (exp patient education/ or exp. counseling/ or exp. teaching/ or (discussion* or coaching or navigation* or navigating or learning or awareness or training or conversation* or engag* or promotion* or story or stories or experienc* or sharing or educator* or education* or educating or encourag* or teaching or counseling or information or knowledge or communicat*). $a b, t i$.$) and (exp interviews/ or exp. questionnaires/ or (qualitative or ethnograph*$ or phenomenol* or grounded theor* or purposive sampl* or hermeneutic* or heuristic ${ }^{*}$ or semiotics or lived experience* ${ }^{*}$ or narrat* or life experience* or cluster sample* or action research or observational method* or content analys* or thematic analys* or constant comparative method* or field stud* or theoretical sampl* or discourse analys* or focus group* or ethnological research or ethnomethodolog* or interview* or mixed method* or mixed model* or mixed design* or survey* or questionnaire* or anecdote*).ab,ti.) 


\section{Appendix 2}

Table 5 Summary of critical appraisal of study quality

\begin{tabular}{|c|c|c|c|c|c|c|c|c|c|}
\hline Domain & $\begin{array}{l}\text { Berry \& } \\
\text { Planalp }\end{array}$ & $\begin{array}{l}\text { Brighton } \\
\text { et al. }\end{array}$ & $\begin{array}{l}\text { Clarke } \\
\text { et al. }\end{array}$ & Foster & $\begin{array}{l}\text { Jones } \\
\text { et al. }\end{array}$ & $\begin{array}{l}\text { Planalp \& } \\
\text { Trost }\end{array}$ & $\begin{array}{l}\text { Planalp } \\
\text { et al. }\end{array}$ & $\begin{array}{l}\text { Rocque } \\
\text { et al. }\end{array}$ & $\begin{array}{l}\text { Seymour } \\
\text { et al. }\end{array}$ \\
\hline Study purpose: Was purpose or research question stated? & Yes & Yes & Yes & Yes & Yes & Yes & Yes & Yes & Yes \\
\hline Literature: Was relevant literature reviewed? & Yes & Yes & Yes & Yes & Yes & Yes & Yes & Yes & Yes \\
\hline Study design: Was a theoretical perspective identified? & Yes & Yes & Yes & Yes & No & Yes & No & Yes & Yes \\
\hline $\begin{array}{l}\text { Sampling: Was the process of purposeful } \\
\text { selection described? }\end{array}$ & No & Yes & Yes & No & Yes & No & No & No & Yes \\
\hline $\begin{array}{l}\text { Was sampling done until redundancy in data } \\
\text { was reached? }\end{array}$ & N.A. & Yes & N.A. & N.A. & N.A. & N.A. & N.A. & N.A. & N.A. \\
\hline Was informed consent obtained? & Yes & Yes & No & No & Yes & N.A. & N.A. & Yes & N.A. \\
\hline Data Collection: Was procedural rigor used? & Yes & Yes & N.A. & No & N.A. & Yes & Yes & Yes & Yes \\
\hline Descriptive clarity: Complete description of site & No & Yes & No & No & Yes & No & No & Yes & Yes \\
\hline Descriptive clarity: Complete description of participant & Yes & Yes & No & No & Yes & Yes & No & Yes & Yes \\
\hline $\begin{array}{l}\text { Description of role of researcher and relationship } \\
\text { with participants }\end{array}$ & No & Yes & Yes & Yes & No & No & No & Yes & Yes \\
\hline Identification of assumption and biases of researcher & No & Yes & No & Yes & No & No & No & Yes & No \\
\hline Analytical rigor: Were data analyses inductive? & No & Yes & N.A. & Yes & Yes & Yes & Yes & Yes & N.A. \\
\hline Were findings consistent with and reflective of data? & Yes & Yes & Yes & Yes & Yes & Yes & Yes & Yes & Yes \\
\hline Auditability: Was a decision trail developed? & N.A. & Yes & N.A. & Yes & No & N.A. & Yes & N.A. & No \\
\hline $\begin{array}{l}\text { Was the process of analyzing the data described } \\
\text { adequately? }\end{array}$ & Yes & Yes & No & N.A. & No & Yes & Yes & Yes & Yes \\
\hline $\begin{array}{l}\text { Theoretical connections: Did a meaningful picture } \\
\text { emerge? }\end{array}$ & No & No & Yes & Yes & No & Yes & No & Yes & Yes \\
\hline $\begin{array}{l}\text { Credibility: Do descriptions and interpretations } \\
\text { of participants capture the phenomenon? }\end{array}$ & Yes & Yes & Yes & Yes & No & No & Yes & Yes & Yes \\
\hline $\begin{array}{l}\text { Transferability: Can the findings be transferred to } \\
\text { other situations? }\end{array}$ & Yes & Yes & No & No & No & Yes & Yes & Yes & Yes \\
\hline $\begin{array}{l}\text { Dependability: Was there consistency between } \\
\text { data and findings? }\end{array}$ & No & Yes & Yes & No & No & Yes & Yes & Yes & Yes \\
\hline $\begin{array}{l}\text { Confirmability: Were strategies employed to } \\
\text { minimize bias? }\end{array}$ & No & Yes & Yes & No & No & No & No & Yes & No \\
\hline $\begin{array}{l}\text { Conclusions: Were conclusions appropriate } \\
\text { given study findings? }\end{array}$ & Yes & Yes & Yes & Yes & Yes & Yes & Yes & Yes & Yes \\
\hline $\begin{array}{l}\text { Implications: Were findings meaningful to } \\
\text { "laypersons" and communication? }\end{array}$ & Yes & Yes & No & Yes & Yes & Yes & Yes & Yes & Yes \\
\hline Total score: & $60 \%$ & $95 \%$ & $61 \%$ & $60 \%$ & $50 \%$ & $68 \%$ & $60 \%$ & $95 \%$ & $84 \%$ \\
\hline
\end{tabular}

Quality appraisal results and scoring of included studies using McMaster University tool

providing ongoing support to maximize and sustain the impact of the layperson's role.

\section{Abbreviations}

UK: United Kingdom; US: United States

\section{Acknowledgements}

This study was presented at the 10th World Research Congress of the European Association for Palliative Care. The abstract is published online in Palliative Medicine (Abstract number P158; https://doi.org/10.1177/0269216318769196).

\section{Funding}

This work was supported in part by the National Institutes of Health [K76AG054782] and Department of Veterans Affairs. The funders had no role in study design, data collection, analysis, interpretation, writing of the manuscript, or decision to submit for publication.

\section{Authors' contributions}

Study design: HL, CJ, SJ, US, KB, KD, and JJ defined the study question, study question, search aims, and methodology used for identification and analysis of data. Data collection: KD conducted a focused study search and JD, AB, and $\mathrm{HL}$ completed study selection. Data analysis: SJ, CJ, US, and KB completed the quality rating for each selected study. JD, $A B$, and $H L$ completed study extraction. ES, JD, AB, SJ, and $\mathrm{HL}$ completed the synthesis of themes. Manuscript preparation: ES, JD, AB, SJ, HL. Critical manuscript revision: CJ, SJ, US, KB, JJ, KD. All authors participated in final revision and have read and approved the manuscript.

Ethics approval and consent to participate

Not applicable. 


\section{Consent for publication}

Not applicable.

\section{Competing interests}

The authors have no potential conflicts of interest with respect to the research, authorship and/or publication of this article.

\section{Publisher's Note}

Springer Nature remains neutral with regard to jurisdictional claims in published maps and institutional affiliations.

\section{Author details}

'Internal Medicine Residency, University of Colorado School of Medicine, University of Colorado Anschutz Medical Campus, Aurora, CO, USA. ${ }^{2}$ University of Colorado Skaggs School of Pharmacy and Pharmaceutical Sciences, University of Colorado Anschutz Medical Campus, Aurora, CO, USA. ${ }^{3}$ VA Eastern Colorado Geriatric Research Education and Clinical Center, Denver, CO, USA. ${ }^{4}$ Division of Geriatric Medicine, University of Colorado School of Medicine, University of Colorado Anschutz Medical Campus, 12631 E. 17th Ave, Mail Stop B179, Aurora, CO 80045, USA. ${ }^{5}$ Health Sciences Library, University of Colorado Anschutz Medical Campus, Aurora, CO, USA. ${ }^{6}$ Division of Hospital Medicine, University of Colorado School of Medicine, Anschutz Medical Campus, Aurora, CO, USA. ${ }^{7}$ College of Nursing, University of Colorado Anschutz Medical Campus, Aurora, CO, USA. ${ }^{8}$ Division of Cardiovascular Medicine, Sarver Heart Center, University of Arizona, Tucson, AZ, USA.

Received: 1 May 2018 Accepted: 31 July 2018

Published online: 06 August 2018

\section{References}

1. Sudore RL, Lum HD, You JJ, Hanson LC, Meier DE, Pantilat SZ, et al. Defining Advance Care Planning for Adults: A consensus definition from a multidisciplinary Delphi panel. J Pain Symptom Manage. 2017:53(5):821-32. e821

2. Brinkman-Stoppelenburg A, Rietjens JA, van der Heide A. The effects of advance care planning on end-of-life care: a systematic review. Palliat Med. 2014;28(8):1000-25.

3. Houben $\mathrm{CH}$, Spruit MA, Groenen MT, Wouters EF, Janssen DJ. Efficacy of advance care planning: a systematic review and meta-analysis. J Am Med Dir Assoc. 2014;15(7):477-89.

4. Institute of Medicine. Dying in America: improving quality and honoring individual preferences near the end of life. Washington, DC: The National Academies Press; 2015. https://doi.org/10.17226/18748.

5. Broadfoot KJ, Candrian C. Relationship-centered care and clinical dialogue: Towards new forms of "care-full" communication. Nat Med J. 2009:1(12):1-2.

6. Sinuff T, Dodek P, You JJ, Barwich D, Tayler C, Downar J, et al. Improving end-of-life communication and decision making: the development of a conceptual framework and quality indicators. J Pain Symptom Manag. 2015; 49(6):1070-80.

7. Sanders C, Seymour J, Clarke A, Gott M, Welton M. Development of a peer education programme for advance end-of-life care planning. Int J Palliat Nurs. 2006;12(5):214. 216-223

8. Calista J, Tjia J. Moving the advance care planning needle with community health workers. Med Care. 2017:55(4):315-8.

9. Fischer SM, Sauaia A, Kutner JS. Patient navigation: a culturally competent strategy to address disparities in palliative care. J Palliat Med. 2007;10(5): 1023-8.

10. Perry E, Swartz J, Brown S, Smith D, Kelly G, Swartz R. Peer mentoring: a culturally sensitive approach to end-of-life planning for long-term dialysis patients. Am J Kidney Dis. 2005:46(1):111-9.

11. Rocque GB, Dionne-Odom JN, Sylvia Huang CH, Niranjan SJ, Williams CP, Jackson $\mathrm{BE}$, et al. Implementation and impact of patient lay navigator-led advance care planning conversations. J Pain Symptom Manag. 2017;53(4): 682-92.

12. Clarke A, Seymour J. "at the foot of a very long ladder": discussing the end of life with older people and informal caregivers. J Pain Symptom Manag. 2010:40(6):857-69.

13. Burbeck R, Candy B, Low J, Rees R. Understanding the role of the volunteer in specialist palliative care: a systematic review and thematic synthesis of qualitative studies. BMC Palliat Care. 2014;13(1):3.
14. Candy B, France R, Low J, Sampson L. Does involving volunteers in the provision of palliative care make a difference to patient and family wellbeing? A systematic review of quantitative and qualitative evidence. Int J Nurs Stud. 2015;52(3):756-68

15. Connell B, Warner G, Weeks LE. The feasibility of creating partnerships between palliative care volunteers and healthcare providers to support rural frail older adults and their families: an integrative review. Am J Hosp Palliat Care. 2016;34(8):786-94.

16. Downe-Wamboldt B, Ellerton ML. A study of the role of hospice volunteers. Hospice J. 1985;1(4):17-31.

17. Luijkx KG, Schols JM. Volunteers in palliative care make a difference. J Palliat Care. 2009;25(1):30-9.

18. Jack BA, Kirton J, Birakurataki J, Merriman A. 'A bridge to the hospice': the impact of a community volunteer programme in Uganda. Palliat Med. 2011; 25(7):706-15.

19. Germain A, Nolan K, Doyle R, Mason S, Gambles M, Chen H, et al. The use of reflective diaries in end of life training programmes: a study exploring the impact of self-reflection on the participants in a volunteer training programme. BMC Palliat Care. 2016;15:28.

20. Brighton LJ, Koffman J, Robinson V, Khan SA, George R, Burman R, Selman LE. End of life could be on any ward really: a qualitative study of hospital volunteers' end-of-life care training needs and learning preferences. Palliat Med. 2017:9:842-52

21. Beasley E, Brooker J, Warren N, Fletcher J, Boyle C, Ventura A, Burney S. The lived experience of volunteering in a palliative care biography service. Palliat Suppor Care. 2015:13(5):1417-25.

22. Planalp S, Trost MR. Communication issues at the end of life: reports from hospice volunteers. Health Commun. 2008;23(3):222-33.

23. Tong A, Flemming K, Mclnnes E, Oliver S, Craig J. Enhancing transparency in reporting the synthesis of qualitative research: ENTREQ. BMC Med Res Methodol. 2012:12:181

24. Thomas J, Harden A. Methods for the thematic synthesis of qualitative research in systematic reviews. BMC Med Res Methodol. 2008:8:45.

25. Letts L, Wilkins S, Law M, Stewart D, Bosch J, Westmorland M. Guidelines for critical review form: Qualitative studies (Version 2.0) [https://srs-mcmaster.ca/ wp-content/uploads/2015/05/Guidelines-for-Critical-Review-FormQualitative-Studies.pdf].

26. Moher D, Liberati A, Tetzlaff J, Altman DG, Group P. Preferred reporting items for systematic reviews and meta-analyses: the PRISMA statement. J Clin Epidemiol. 2009;62(10):1006-12.

27. Planalp S, Trost MR, Berry PH. Spiritual feasts: meaningful conversations between hospice volunteers and patients. Am J Hosp Palliat Med. 2011; 28(7):483-6.

28. Foster E. Lessons we learned: stories of volunteer-patient communication in hospice. J Age Ident. 2002;7(4):245-56.

29. Jones P, Heaps K, Rattigan C, Di M-M. Advance care planning in a UK hospice: the experiences of trained volunteers. Eur J Palliat Care. 2015;22(3):144-51.

30. Berry P, Planalp S. Ethical issues for hospice volunteers. Am J Hosp Palliat Med. 2008;25(6):458-62.

31. Litzelman DK, Inui TS, Schmitt-Wendholt KM, Perkins A, Griffin WJ, Cottingham AH, Ivy SS. Clarifying values and preferences for care near the end of life: the role of a new lay workforce. J Community Health. 2017:42(5):926-34.

32. Weeks LE, Macquarrie C, Bryanton O. Hospice palliative care volunteers: a unique care link. J Palliat Care. 2008;24(2):85-93.

33. Gasiorek J, Giles H. Communication, volunteering, and aging: a research agenda. Int J Commun-Us. 2013;7:2659-77.

34. Claxton-Oldfield S, Claxton-Oldfield J. The impact of volunteering in hospice palliative care. Am J Hosp Palliat Med. 2007;24(4):259-63.

35. Clary EG, Snyder M, Ridge RD, Copeland J, Stukas AA, Haugen J, Miene P. Understanding and assessing the motivations of volunteers: a functional approach. J Pers Soc Psychol. 1998;74(6):1516-30.

36. Clarke A, Sanders C, Seymour J, Gott M, Welton M. Evaluating a peer education program for advance end-of-life care planning for older adults: the peer educators' perspective. Int J Disabil Human Dev. 2009;8(1):33-41.

37. Seymour JE, Almack K, Kennedy S, Froggatt K. Peer education for advance care planning: volunteers' perspectives on training and community engagement activities. Health Expect. 2013;16(1):43-55 